See Article page 239 in the December 2020 issue.

\section{Commentary: On aortic uncrossing: New variation on an old controversy}

\author{
Reilly Hobbs, MD, MBS, and Ming-Sing Si, MD
}

Circumflex retroesophageal aorta is a rare congenital anomaly in which a right aortic arch runs posterior to the trachea and esophagus and forms a vascular ring with a left-sided ligament. The exact incidence of this lesion is unknown, and review of the literature shows only isolated case reports and small case series. ${ }^{1,2}$ The aortic uncrossing procedure is the standard of care for symptomatic patients and involves division of the ligamentum with translocation of the descending thoracic aorta to the ascending aorta-anterior to the trachea and esophagus. All previously reported cases have required periods of circulatory arrest with aortic crossclamping.

Said and colleagues ${ }^{3}$ report the use of normothermic continuous total-body perfusion during an aortic uncrossing procedure. To accomplish this, both the innominate artery and descending thoracic aorta were cannulated, which allowed for total-body perfusion during the uncrossing procedure with the avoidance of circulatory and cardioplegic arrest. This is a novel application for this perfusion strategy for the treatment of circumflex aorta. However, similar cannulation strategies have been described in aortic arch reconstruction surgeries as well as the Norwood procedure. ${ }^{4}$ Readers will appreciate the accompanying video that the authors have prepared, which is informative of not just the cannulation approach but the uncrossing procedure as well.

Numerous cardiopulmonary bypass cannulation strategies have been reported for the treatment of neonatal and

\footnotetext{
From the Section of Pediatric Cardiovascular Surgery, Department of Cardiac Surgery, University of Michigan, Ann Arbor, Mich.

Disclosures: The authors reported no conflicts of interest.

The Journal policy requires editors and reviewers to disclose conflicts of interest and to decline handling or reviewing manuscripts for which they may have a conflict of interest. The editors and reviewers of this article have no conflicts of interest.

Received for publication Nov 12, 2020; revisions received Nov 12, 2020; accepted for publication Nov 13, 2020; available ahead of print Nov 18, 2020.

Address for reprints: Ming-Sing Si, MD, 11-735 C.S. Mott Children's Hospital SPC 4204, 1540 E Hospital Dr, Ann Arbor, MI, 48109-4204 (E-mail: mingsing @umich. edu).

JTCVS Techniques 2021;5:97-8

2666-2507

Copyright (C) 2020 The Authors. Published by Elsevier Inc. on behalf of The American Association for Thoracic Surgery. This is an open access article under the CC BY-NCND license (http://creativecommons.org/licenses/by-nc-nd/4.0/).

https://doi.org/10.1016/j.xjtc.2020.11.011
}

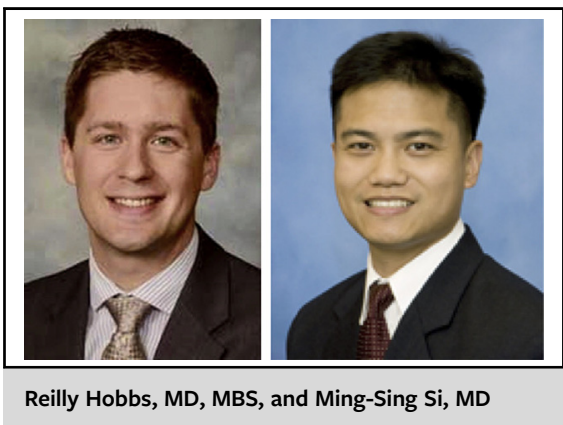

CENTRAL MESSAGE

Aortic uncrossing procedure for a circumflex aorta treated with beating-heart and total-body perfusion highlights a continuing controversy.

infant aortic arch operations. ${ }^{4,5}$ Advocates for continuous and regional perfusion strategies cite that circulatory arrest is associated with increased end-organ dysfunction, postoperative bleeding, and neurologic injury. ${ }^{4}$ Nevertheless, despite the intuitive risks, no compelling literature is available linking the use of hypothermic circulatory arrest with worse perioperative outcome or neurologic injury when compared with alternative perfusion strategies. ${ }^{6,7}$ However regional perfusion may be beneficial for the lower-body organs, which may not tolerate ischemia as well or may not be as regenerative as the neonatal brain. This highlights one of the major controversies in our field and underscores the need for a well-designed clinical trial or different-aged subjects that uses sensitive biomarkers and other cutting-edge techniques to assess organ injury that may result from circulatory arrest and regional perfusion.

\section{References}

1. Planche C, Lacour-Gayet F. Aortic uncrossing for compressive circumflex aorta. 3 cases [in French]. Presse Med. 1984;13:1331-2.

2. Kamran A, Friedman KG, Jennings RW, Baird CW. Aortic uncrossing and tracheobronchopexy corrects tracheal compression and tracheobronchomalacia associated with circumflex aortic arch. J Thorac Cardiovasc Surg. 2020;160:796-804.

3. Said SM, Marey G, Jakubowski L, Miranda C. Aortic uncrossing procedure: when the right becomes left. J Thorac Cardiovasc Surg Tech. 2020;4:239-42.

4. Lodge AJ, Andersen ND, Turek JW. Recent advances in congenital heart surgery: alternative perfusion strategies for infant aortic arch repair. Curr Cardiol Rep. 2019;21:13.

5. Meyer DB, Jacobs JP, Hill K, Wallace AS, Bateson B, Jacobs ML. Variation in perfusion strategies for neonatal and infant aortic arch repair: contemporary practice in the STS congenital heart surgery database. World J Pediatr Congenit Heart Surg. 2016;7:638-44. 
6. Algra SO, Jansen NJ, van der Tweel I, Schouten AN, Groenendaal F, Toet $\mathrm{M}$, et al. Neurological injury after neonatal cardiac surgery: a randomized, controlled trial of 2 perfusion techniques. Circulation. 2014; 129:224-33.
7. Goldberg CS, Bove EL, Devaney EJ, Mollen E, Schwartz E, Tindall S, et al. A randomized clinical trial of regional cerebral perfusion versus deep hypothermic circulatory arrest: outcomes for infants with functional single ventricle. J Thorac Cardiovasc Surg. 2007; 133:880-7. 